\title{
Managing everyday life with chronic pain and interaction with healthcare: a qualitative study
}

\section{Ebba Ranås}

Department of Geriatrics, Sahlgrenska University Hospital, Gothenburg

\section{Amanda Dahlrot}

Department of Surgery, Sahlgrenska University Hospital, Gothenburg

\section{Anna Grimby-Ekman}

School of Public Health and Community Medicine, Institute of Medicine, Sahlgrenska Academy, University of Gothenburg

Linda Ahlstrom ( $\square$ linda.ahlstrom@gu.se)

Health and Care Sciences, Sahlgrenska Academy, University of Gothenburg

\section{Research Article}

Keywords: chronic pain, healthcare

Posted Date: March 1st, 2021

DOl: https://doi.org/10.21203/rs.3.rs-283633/v1

License: (1) (1) This work is licensed under a Creative Commons Attribution 4.0 International License. Read Full License 


\section{Background}

For individuals living with chronic pain, contact with primary care organisations forms a major part of their everyday lives. Of those individuals, three-fifths $(60 \%)$ seek primary care for help and support 2 to 9 times every 6 months (1). In Europe, nearly one in five people (19\%) suffers from chronic pain (1), and the condition is especially prevalent among women and older adults (2). Added to that, chronic pain places a burden on society. In Sweden, for instance, the estimated mean cost for one person living with chronic pain is $€ 6400$ per year (3).

Although chronic pain typically implies long-term suffering for the individuals affected, its characteristics differ, and its impacts include general interference, disability, stress and perceived lack of control (4). The sensation of pain is neither strictly physical nor psychological but commonly described as consisting of three parts - the sensory, the cognitive and the behavioural-and is thus always subjective $(5,6)$. Chronic pain in particular is associated with multi-morbidity, sleep problems, depression, anxiety, reduced quality of life and often being on sick leave $(2,7,8)$. Beyond that, one of every three individuals experiencing chronic pain has indicated that their pain limits their capacity to live their lives freely and to be independent, and, as a consequence, they often feel misunderstood by their family and friends (1). Meanwhile, in their interactions with others, individuals living with chronic pain often encounter a lack of empathy and disbelief in their pain $(1,8)$. At the same time, outcomes of coping with chronic pain can depend upon the individuals' approaches towards their pain, their defensive or offensive behaviours and their choices based upon their self-efficacy. In general, people's perceived self-efficacy - that is, their belief that they can handle specific situations involving behaviours affecting their health—can predict their health outcomes (10). 
Working in healthcare means meeting individuals who suffer, particularly from pain.

Although continually interacting with the suffering of others is frequently discomforting and requires courage, avoiding it is a disservice to the people who are suffering, especially when meeting their individual needs to provide some relief usually does not require extensive effort (11). To aid in that task, person-centred care takes stock of the individual's spiritual, existential, social, physical and psychological needs. As a result, understanding the individual's experience, and their personal stories can enable healthcare personnel to provide appropriate support and thereby promote health and well-being (12). In that light, even when their symptoms and diseases seem homogeneous, patients should be regarded as active multidimensional individuals and their care plans should be individually tailored (13). Nevertheless, recent research has shown that up to $80 \%$ of primary care physicians have expressed that individuals living with chronic pain do not receive optimal treatment or care (14). Thus, it remains necessary to investigate how individuals living with chronic pain experience their interactions with healthcare organisations and how they believe that they can be supported.

Answering that call, we designed a study to examine how individuals living with chronic pain manage their everyday lives and, from their perspectives, how primary care organisations should support them.

\section{Methods}

\section{Study design}

To identify how individuals with chronic pain manage their everyday lives and gather their thoughts on how primary care organisations should support them, we conducted a qualitative 
study following an open inductive approach. In that approach, participants' experiences were elicited by means of written personal narratives and focus group interviews, after which data were analysed in qualitative content analysis (15).

\section{Setting}

The study formed part of Pain Care Vision 2030, a project to improve primary care support in Västra Götalandsregionen, one of Sweden's largest regions, by promoting person-centred, evidence-based care for individuals living with chronic pain. Throughout Sweden, healthcare is primarily funded by taxes and care is provided by the public sector (16). Our study involved gathering data in a focus group consisting of individuals with unique experiences with living with chronic pain.

\section{Sample}

All participants received information about the study by being members of patients' organisations, either the Headache Association or Rheumatism Association. In accordance with guidelines for ethical research (17), the participants received information about the project and study via email before consenting to participate, as well as orally at the time of the focus group, and written ethical guidelines at the beginning of the focus group interview from the project leader. Participants were aware that attending the focus group implied their informal consent to participate in the study.

\section{Data collection}

Twenty-one individuals registered to participate in the study via email. When participants subsequently registered for focus group discussions, they were requested to write about their experiences with living with chronic pain in narratives that would later be used as data to gain insights into their individual experiences. Ultimately, only 15 of the 21 registered individuals 
attended the focus group interviews; the remaining six did not take participate due to illness ( $n$ $=2)$, practical reasons $(n=2)$, pain related fatigue $(n=1)$ or an unknown reason $(n=1)$. All participants wrote and spoke Swedish fluently.

The focus group activities, consisting of three parts, were led by a moderator who facilitated the discussion but did not participate in the project. In the first part, participants were grouped in pairs where they in the pair were asked to interview each other, one interviewing the other person and then, about how they manage situations at home, outside their homes, in healthcare encounters and otherwise in their everyday lives in relation to their pain. During the interviews, participants took notes about their interviewees and later presented their own experience in an all-group discussion led by the moderator. In the second part, in groups of four or five individuals, participants were asked to describe what their ideal encounter in primary care would be as other group members took notes on their descriptions to be presented later in another moderator-led all-group discussion. In the third part, participants were presented with three innovation-driven projects addressing care for individuals living with chronic pain and asked to write down their reactions and ideas about the projects to be presented later in a final moderator-led all-group discussion. After the activities, the moderator synthesised an overview of the discussions with reference to the participants' written materials.

\section{Qualitative analysis}

The data from the participants' notes from the focus group discussions, the moderator's synthesis of all three parts of the focus group activities and the narratives written by the participants were subjected to qualitative content analysis following Graneheim and Lundman, which involved the abstraction and interpretation of the data on various levels (15). 
In that process, all of the data were read several times in order to gain a sense of the whole, after which meaning units were extracted in accordance with the study's aim and numbered according to the origin of the data in the focus group; for instance, data from the first part, "A", were labelled "A1" and "A2" and so on, while data from the second part were labelled "B1" and "B2" and so on. Next, those meaning units were independently condensed, abstracted and coded by AD and ER and, in a subsequent step, further discussed and compared to verify their alignment with the study's context. Once the codes were grouped by similarities and differences into subcategories and, in turn, categories, they were openly discussed among the authors (Table 1). In a later phase entailing latent analyses, the underlying meaning of the content in the categories enabled the identification of an overarching theme and two sub-themes. Throughout the study period, that iterative process was analysed, compared and discussed within the research group to ensure credibility according to standards for reporting on qualitative research, which were also observed when writing this article (18).

Table 1. Examples of qualitative content analysis from comments of individuals living with chronic pain

\begin{tabular}{llll}
\hline Meaning units & $\begin{array}{l}\text { Condensed } \\
\text { meaning unit }\end{array}$ & Subcategory & Category \\
\hline $\begin{array}{l}\text { "I think that a holistic approach is needed to be able to } \\
\text { grasp every patient's situation". }\end{array}$ & $\begin{array}{l}\text { Holistic perspectives } \\
\text { to help patients }\end{array}$ & $\begin{array}{l}\text { Need for a holistic } \\
\text { view }\end{array}$ & $\begin{array}{l}\text { Being treated with } \\
\text { respect }\end{array}$ \\
$\begin{array}{l}\text { "I placed the monitor and keyboard under my desk and } \\
\text { lied down on the floor and began to work. It felt like the } \\
\text { best solution in that moment". }\end{array}$ & $\begin{array}{l}\text { Mobilising and doing } \\
\text { what was needed }\end{array}$ & $\begin{array}{l}\text { Optimising body } \\
\text { positions }\end{array}$ & $\begin{array}{l}\text { Finding } \\
\text { empowerment }\end{array}$ \\
\hline
\end{tabular}

\section{Results}

Of the 21 individuals with chronic pain registered to participate in the study, 15 attended the focus group discussion: 3 men and 12 women. The participants' medical diagnoses were diverse, and their ages ranged from 33 to 79 years. The overarching theme identified was that individuals with chronic pain develop adaptability in managing their everyday lives (Table 2), 
which derived from two sub-themes-one concerning the person's body and soul, the other concerning the person's interactions with healthcare —with four categories and 13 subcategories. More specifically, the first sub-theme captures how such individuals use their bodies and souls to condition themselves and adapt to the people around them, take control of their everyday lives (i.e. by initiating better healthcare, planning their everyday lives and seeking support and assistance) and find empowerment (i.e. by optimising body positions, using complementary treatment strategies and finding inner strength). By contrast, the second sub-theme captures how the individuals develop adaptability when interacting with healthcare personnel and primary care organisations, their experiences with such interaction and the need to be treated with respect. Along those lines, their contact with primary care organisations revealed various shortcomings, and the participants requested a greater availability of primary care, continuity in care, inter-professional care and digital tools as a technological complement to their care. Added to that, healthcare personnel were sometimes perceived as demeaning when they did not treat the individuals living with chronic pain respectfully. Most often, the participants advocated better partnerships in their interactions with healthcare personnel out of a desire to be taken seriously and their recognition of the need for holistic understanding. 
Table 2. Examples of how individuals with chronic pain manage their everyday lives and their recommendations for what primary care should involve in various subcategories, categories and sub-themes

\begin{tabular}{|c|c|c|c|}
\hline Subcategory & Category & Sub-theme & Theme \\
\hline Initiating better healthcare & \multirow{3}{*}{$\begin{array}{c}\text { Taking charge of their } \\
\text { everyday lives }\end{array}$} & \multirow{6}{*}{$\begin{array}{l}\text { The person's body and } \\
\text { soul }\end{array}$} & \multirow{13}{*}{$\begin{array}{l}\text { Developing adaptability tc } \\
\text { manage everyday life }\end{array}$} \\
\hline Planning everyday lives & & & \\
\hline Seeking support and assistance & & & \\
\hline Optimising body positions & \multirow{3}{*}{ Finding empowerment } & & \\
\hline $\begin{array}{l}\text { Using complementary treatment } \\
\text { strategies }\end{array}$ & & & \\
\hline Finding inner strength & & & \\
\hline $\begin{array}{c}\text { Boosting the availability of primary } \\
\text { care }\end{array}$ & \multirow{4}{*}{$\begin{array}{c}\text { Interacting with primary care } \\
\text { organisations }\end{array}$} & \multirow{7}{*}{$\begin{array}{l}\text { The person's interactions } \\
\text { with healthcare }\end{array}$} & \\
\hline Boosting continuity of care & & & \\
\hline Boosting inter-professional care & & & \\
\hline $\begin{array}{l}\text { Providing digital tools to complement } \\
\text { treatment strategies }\end{array}$ & & & \\
\hline Seeking better partnerships & \multirow{3}{*}{ Being treated with respect } & & \\
\hline Wanting to be taken seriously & & & \\
\hline Needing holistic understanding & & & \\
\hline
\end{tabular}

\section{Sub-theme 1: The person's body and soul}

The first sub-theme captures how individuals with chronic pain use their bodies and souls to condition themselves and adapt to the people around them.

\section{Taking charge of their everyday lives}

The individuals with chronic pain reported adapting to their situations by actively planning their everyday lives. While living with their pain, they have realised which activities require resting the day before and the day after and how much work, cleaning and cooking they can accomplish during a given day or week: "I understand how it fits together as I've acquired more knowledge about my disease, lived a more balanced life and seen that it makes a positive difference". They also described taking charge of their everyday lives by initiating 
better healthcare. To that end, they generally seek information about their pain, share that information with healthcare personnel, write down their questions and experiences and are persistent in questioning their care and giving suggestions about it. When they have felt unsatisfied with their care, they have sought treatment from another healthcare provider and/or contacted other professionals to serve on their individualised inter-professional pain management teams. As one participant put it, "As a patient, it's necessary for me to know a lot and to be persistent in order to make things happen". Participants likewise expressed that being active in seeking support and assistance for themselves was imperative. Some have taken strength from their families and friends to keep fighting for appropriate healthcare, while others have sought support from their healthcare providers and found it, for example, by being introduced to associations for individuals with chronic pain or by attending informational meetings about their condition. However, when their healthcare providers have not provided the support desired, they have felt as though they have been left to suffer and cope with their pain on their own.

\section{Finding empowerment}

In managing their everyday lives while living with chronic pain, participants used different practical techniques to find empowerment. Optimising their body positions was one such technique used in various settings. Some participants described taking longer routes on public transportation in order to optimise their body positions by sitting down, which typically delays their other plans for the day. Others described optimising their workspaces and their sleeping arrangements: "I placed the monitor and keyboard under my desk and lied down on the floor and began to work". Altogether, the constant need for optimisation places stress on their mental and physical wellbeing. Another technique for finding empowerment was using complementary treatment strategies, including naturopathy, acupuncture, massage, cognitivebehavioural therapy, yoga, walks, jogs, strength training, physiotherapy, swimming, 
mindfulness, qigong, breathing exercises, transcutaneous electrical nerve stimulation, using a heat pad or using a mouthguard. Finding inner strength within themselves to make the best of situations also empowered them to endure mistreatment from healthcare personnel. By actively ignoring the negative influences of them being mistreated and focusing solely on the good, they found themselves in better mental states. However, no matter how much inner strength they could muster, the ordeal of living with chronic pain and its consequences was often overwhelming and created a feeling of hopelessness: "It's not easy living this kind of life. You have to be healthy to cope with being sick".

\section{Sub-theme 2: The person's interactions with healthcare}

The second sub-theme explains that individuals with chronic pain wish for changes in the primary care organisation, so they don't have to adapt themselves, and to be treated with respect.

\section{Interacting with primary care organisations}

Interacting with primary care organisations is a major, highly influential part of the everyday lives of individuals living with chronic pain. In that relationship, the amount of time needed to be correctly diagnosed, identify an appropriate treatment or make an appointment with an appropriate healthcare provider, however, diminishes trust in the primary care organisations. In response, some participants reported seeking treatment in other countries in order to procure an appropriate healthcare provider. Not wanting "others to go down the same path through the healthcare system", individuals with chronic pain often expressed a wish for more flexible, more frequently available primary care, including by simplifying the technology required and diversifying means of contact. Simplifying the process for applying for sick leave - for instance, by allowing the process to be completed over the phone instead of necessitating an in-person meeting — was also mentioned as a way to ease their everyday 
lives. Another suggestion was simplifying the process of booking appointments with doctors and using a medical records system shared by all healthcare providers.

Participants also stressed the need for improved continuity of care in their primary care organisations. Because being treated by the same physician creates trust and a feeling of safety, particularly by preventing the need to restate their situations and recount their experiences, follow-up appointments and treatments, although rare, are greatly appreciated because they mitigate concerns of being forgotten by the primary care organisation. Interprofessional care is additionally appreciated but seldom offered by primary care organisations. In that light, participants stated being unable to expect anything but strict medical treatment from primary care, which has left them with a feeling of hopelessness. By working with more inter-professional teams, however, they argued that the complexity of their pain could be viewed in a different light, namely not only as a patient with chronic pain but also as a whole person. To complement those strategies, digital tools—for example, digital pain scales - can offer effective ways to support the treatment of chronic pain. Participants highlighted the possibility for the tools to make primary care organisations more accessible but also their fear that the tools would replace instead of complement physical appointments. Some also worried that the tools would bias clinical assessments in negative ways and allow healthcare personnel to overlook the people in front of them while instead judging them purely with reference to the information received from the tools.

\section{Being treated with respect}

The participants expressing wanting better partnerships and treatment when in contact with their primary care organisations. Although some had experienced support from primary care organisations as helpful and acknowledged being listened to and cared for by their healthcare providers, they and others also indicated wanting to be taken seriously when seeking help for 
their pain. Fuelling their frustration, they reported being met with disbelief when expressing their pain and even being described as healthy by physicians on their medical records despite having expressed chronic pain during past appointments: "My subjective experience doesn't matter. ... It's frustrating to not be listened to". Participants also described judgemental attitudes among their healthcare providers that had influenced their treatment. Some providers had even allegedly accused participants of being afraid to work or had called them "drug abusers". Participants stated sometimes preferring to visit doctors not natively from Sweden, who seemed to judge them less and would never say, as one participant imagined, "'You've had your dose. Now calm down"”. To improve their partnerships with healthcare providers, the participants voiced the need for holistic understanding, as well as more equal healthcare in which everyone, regardless of symptoms, receives respect and person-centred care.

\section{Discussion}

Our findings clarify the ways in which individuals living with chronic pain have to adapt and become experts in managing their everyday lives in order to ease the strain on both their bodies and souls. They also reveal the need for such individuals to take the lead in collaborating with healthcare organisations.

In general, people require support and encouragement from their environments, which can be obtained in interactions with healthcare personnel, especially in primary care. Developing adaptability to that end is a long process of learning, one that could be more efficient if provided with sufficient support. For individuals living with chronic pain, such adaptation should occur as rapidly as possible due to ever-shifting circumstances in their daily lives. In that case, becoming able to live with chronic pain requires assistance with everyday matters, including in communication with healthcare personnel about activities, prescriptions for painkillers, sick leave certificates, support from other professionals and, at time, even simply 
about their pain. For individuals living with chronic pain (19), performing everyday activities requires adapting their bodies and souls by exercising, planning chores and their social lives and making time for rest (1).

Similar to our findings, the results of other work have shown how individuals living with chronic pain have to take responsibility for their own care in order to enable better care (20, 21). Likewise, when interacting with healthcare organisations, individuals living with chronic pain have relied upon their inner strength as a factor of adaptability. In past interviews, such individuals have listed stubbornness, strength and actively informing healthcare personnel as prerequisites in interacting with healthcare organisations and described having to continually generate inner strength while fighting illness was exhausting (20). Individuals with chronic pain often have to fight to receive care (20), and that same behaviour emerged in our study's findings, presented as the category of taking charge of their everyday lives.

The participants in our study showed different strategies when handling everyday life with chronic pain. Some individuals felt mentally defeated, whilst some acted as they had taken control of managing their everyday lives by an adapting optimistic mind-set and mobilising creativity, decisiveness, determination and visionary thinking. The later characterisation describes individuals with high self-efficacy. When managing chronic pain, incorporating self-efficacy is the strategy with the most empirical support (22) and is especially valuable in coping with severe pain and relieving it. However, for people with little confidence in their ability to perform tasks needed to manage pain in their everyday lives (i.e. low self-efficacy), the experience of pain is worse than for individuals with high pain self-efficacy. Other evidence suggests that pain-related disabilities can often be mitigated by high levels of selfefficacy, which underscores how developing self-efficacy could be a supplementary technique 
in treating chronic pain (23). Indeed, individuals with chronic pain often behaviourally react to living with such pain in ways characterised as "mental defeat"" (24); they may experience pain as their worst enemy, one that interferes with their autonomy and integrity, which can propagate mind-sets strongly associated with low pain self-efficacy (4).

A particularly good context in which to promote the self-efficacy of individuals living with chronic pain is the rehabilitation process. Therein, person-centred motivational interviewing is a method that healthcare professionals can use to promote changes in behaviour, as well as motivation and willingness for change, and thereby improve pain self-efficacy. As the data in our study suggested, however, that process for individuals already adapting to everyday life requires extraordinary effort and overcoming rather high hurdles. Healthcare organisations, ought to enable and support individuals with chronic pain to adapt in order to manage their everyday. One way could be, as a systematic review has shown, motivational interviewing. Which increases adherence to treatment and possibly decreases pain, but further research on that topic is necessary (25). Healthcare workers should be prepared to thoroughly assess individuals living with chronic pain by listening to their subjective experiences while observing their objective signs of pain (11). Likewise, participants in our study expressed the importance of being taken seriously and not to be disbelieved, as previously shown to be pivotal in investigating pain and strengthening the sense of partnership in healthcare encounters (26). After all, an aspect of person-centred care is respecting the person seeking care and acknowledging their experiences as related by them (12). If the person wants to be taken seriously but is not, then the discrepancy can negatively affect the patient-caregiver relationship in the moment and in future interactions (27). By contrast, interactions in which healthcare workers have asked patients about how pain is affecting their daily activities, relationships and ability to work have served to intensify their feeling of being supported (28). 
Therefore, taking a holistic perspective on approaching and treating patients, as participants in our study recommended, could be in the interest of patients and healthcare personnel alike $(20,29)$.

Individuals with chronic pain have described how preconceptions about their pain heavily influence their encounters with primary care organisations and that they often feel judged and ignored due to their illness (20), which can cause a feeling of humiliation and intensify the anguish that comes with chronic pain (30). In response, healthcare personnel need to be aware of their power to sharpen or alleviate the suffering of individuals living with chronic pain, trust their narratives about their experiences with pain and take them seriously. At the same time, individuals living with chronic pain have described interacting with healthcare personnel as being difficult, as exemplified in their often being requested to rate their pain on a scale (31), when pain is in fact more diverse and affects everyday life in so many more ways than a number could ever capture. Experiencing that healthcare workers rarely see the complexity and dimensions of their pain, they have expressed wanting to be believed, to be seen as experts of their own pain, to be understood from a holistic perspective and to forge partnership and continuity of care. To that end, regular check-ups over the phone from healthcare personnel can help individuals living with chronic pain to experience greater will and feeling of power in managing struggles in their everyday lives (32).

In our study's focus group, digital tools also emerged as a means of supporting contact with healthcare organisations, provided that they do not wholly replace in-person meetings with primary care personnel. Registered nurses working in primary care organisations have been described as offering sufficient support for individuals living with chronic pain, because they showed empathy, were perceived as being helpful and, unlike physicians, had time to listen to 
their experiences and thereby offer much-needed emotional support (32). In our study, participants wanted more holistic, person-centred care — care that the person seeking care truly needs — which healthcare personnel can offer during healthcare encounters by, for example, simply listening to the patient's story (10).

\section{Methodological discussion}

Although the focus group comprised individuals of varying socio-economic status and ethnicity, we could not control their recruitment or analyse such differences because the material was anonymised. Examining them, however, would have added variety and afforded an opportunity for more in-depth knowledge. At the same time, because most participants12 out of 15 -were women and more men would have thus been desirable for the sample, more women in fact live with chronic pain than men. For instance, during recruitment, the information provided in the invitation was the same for all potential participants, all of whom were members of patients' organisations. For that reason, we lacked information regarding the number of invited individuals and how they received their invitations, which could have affected the trustworthiness and credibility of our findings (15). In particular, because they were already engaged in managing chronic pain and/or adapting their everyday lives, the focus group discussion could have been affected by their interest in changing how their healthcare was provided. By contrast, it would be valuable to interview individuals with new symptoms of chronic pain about ways of supporting them in their adaptation.

Focus groups are designed to generate discussion about topics that all participants have experience with and thus elicit reactions and associations that can extend and deepen current understandings of the topics. In our study, using participants individual stories indeed enabled a deeper understanding of the context of the material. Beyond that, a benefit of dividing the 
focus group of 15 individuals into smaller groups was that everyone received the opportunity to speak their minds. Because all of the topics discussed in the smaller groups were addressed in the large group, the moderator's synthesis was deemed to have represented the focus group discussion well. A flaw in the method, however, was that the moderator was not involved in all of the smaller group discussions. Moreover, to achieve theoretical saturation, the discussions should have continued until they no longer generated new information, which was likely not the case in our study, because the moderator had to interrupt several discussions due to time constraints. Achieving theoretical saturation also benefits from having more focus group discussions across a longer time frame. As an advantage, however, the authors were not present during the focus group discussions, meaning that the data provided the participants were not influenced by their presence.

During the analysing process, the derived categories were assessed in light of the meaning units to ensure that relevant data were sorted into the right category. For added trustworthiness, some meaning units are quoted in the presentation of results (15). To promote dependability, the categories where controlled to ensure that meaning units and codes included in each and that the rules for differentiating the categories were clear (33). Afterwards, a discussion regarding how the context represented in the data, categories and themes aligns with the focus group discussion was held with the project leader, AGE, who was present during the focus group discussion. Involving four researchers in data analysis allowed different interpretation of the data, while discussing alternative interpretations during the process enabled consensus and thus dependability (33). As registered nurses, AD, ER and LA have previously cared for individuals living with chronic pain, which naturally influenced their interpretation of the data (15), and they therefore tried their utmost to be professional during analysis. Last, the transferability of the findings extends to others coping with chronic 
pain in their everyday lives and their interactions with healthcare organisations, especially in healthcare systems similar to Sweden's.

\section{Future research}

A recurrent finding in this article and other articles $(1,9)$ is that not all healthcare workers trust individuals with chronic pain. However, the responsibilities of healthcare personnel include viewing each patient as a complete person, not merely a collection of symptoms. It would therefore be fascinating to examine what exactly prevents healthcare workers from doing what they are trained to do. At the same time, our study revealed the lack of personcentred care in participants' interactions with primary care organisations. In that light, it would be interesting to also examine how person-centred primary care could benefit the outcomes for individuals living with chronic pain.

\section{Conclusion}

To manage their everyday lives, the challenges that accompany living with chronic pain and interactions with healthcare organisations, individuals living with chronic pain have to develop adaptability. Although such individuals indeed bear great responsibility for themselves, healthcare personnel can ease that burden by facilitating more flexible, more available collaboration with them. Moreover, by implementing and practising person-centred care, primary care organisations can offer individuals living with chronic pain the support that they need to develop adaptability. However, to that end, healthcare personnel need more knowledge about supporting individuals living with chronic pain in order to ease their suffering.

\section{Declarations}




\section{Ethics approval and consent to participate}

All participants were informed that participation was voluntary and that they could withdraw from the study at any time, without any explanation, in accordance with the Declaration of Helsinki (17). The participants voluntarily consented to participate by replying, via email, to the project leader after receiving written and oral information about the project from their patients' associations (i.e. Headache Association and Rheumatism Association). In the focus groups, participants were informed that any recorded information would be documented as anonymous data in a non-traceable form. Under the Swedish Act Concerning the Ethical Review of Research Involving Humans (No 2003:460), our study did not require ethical approval, and thus participants did not sign any informed consent forms. Instead, participants consented to participate by voluntarily attending the focus group interviews.

\section{Consent for publication}

No individual is identifiable from any quotations or reported data in this manuscript. All saved data and materials from the focus group discussion and notes were anonymised by the moderator.

\section{Availability of data and materials}

The data used and/or analysed in the study are available from the project leader, AGE, upon request.

\section{Competing interests}

The authors declare that they have no competing interests.

\section{Funding}


The authors wish to thank the Swedish Governmental Agency for Innovation Systems and the Swedish Rheumatism Association for funding the study.

\section{Authors' contributions}

A3 initiated and conceived the Pain Care Vision 2030 study. This study formed part of that and A1, A2, and A4 participated in this study design. All authors analysed data. A1 and A2 wrote the first draft of the manuscript, after which A4 finalised the manuscript in its current form. All authors critically reviewed the manuscript and provided comments to improve the manuscript's content. All authors also read and approved the final version of the manuscript.

\section{Acknowledgements}

The authors wish to extend their deepest thanks to all individuals with chronic pain who participated and sharing their stories in our study.

\section{Authors' details}

$\mathrm{XXX}$

\section{References}

1. Breivik H, Collett B, Ventafridda V, Cohen R, Gallacher D. Survey of chronic pain in Europe: prevalence, impact on daily life, and treatment. Eur J Pain. 2006;10(4):287-333.

2. Mills SEE, Nicolson KP, Smith BH. Chronic pain: a review of its epidemiology and associated factors in population-based studies. Br J Anaesth. 2019;123(2):273-83.

3. Gustavsson A, Bjorkman J, Ljungcrantz C, Rhodin A, Rivano-Fischer M, Sjolund KF, et al. Socio-economic burden of patients with a diagnosis related to chronic pain-register data of 840,000 Swedish patients. Eur J Pain. 2012;16(2):289-99. 
4. Hazeldine-Baker CE, Salkovskis PM, Osborn M, Gauntlett-Gilbert J. Understanding the link between feelings of mental defeat, self-efficacy and the experience of chronic pain. Br J Pain. 2018;12(2):87-94.

5. IASP International Association for the Study of Pain. IASP Terminology 1994 [updated 2017-12-14; cited 2019-10-11. Available from: https://www.iasppain.org/terminology?navItemNumber=576\#Pain.

6. McCaffery M. Nursing Management of the Patient with Pain. 2 ed. J B Lippincott: Philadelphia; 1979.

7. SBU. Rehabilitering vid långvarig smärta. En systematisk litteraturöversikt [Chronic Pain and Rehabilitation. A systematic review]. SBU-report no 198. Stockholm: Swedish agency for health technology assessment and assessment of social services; 2010.

8. Jaremo P, Arman M, Gerdle B, Larsson B, Gottberg K. Illness beliefs among patients with chronic widespread pain - Associations with self-reported health status, anxiety and depressive symptoms and impact of pain. BMC Psychology. 2017;5(24).

9. Upshur CC, Bacigalupe G, Luckmann R. 'They don't want anything to do with you': Patient views of primary care management of chronic pain. Pain Medicine. 2010;11(12):1791-8.

10. Bandura A, Adams N. Analysis of self-efficacy theory of behavioural change. Cognitive Therapy and Research. 1977;1(4):287-310.

11. Arman, M., \& Rehnsfeldt, A. The little extra that alleviates suffering. Nurs Ethics. 2007;14(3): 372-386.

12. Ekman I, Swedberg K, Taft C, Lindseth A, Norberg A, Brink E, et al. Person-Centered Care-Ready for Prime Time. Euro J Card Nurs. 2011; 10(4): 248-

51. https://doi.org/10.1016/j.ejcnurse.2011.06.008 
13. Hakansson Eklund J, Holmstrom IK, Kumlin T, Kaminsky E, Skoglund K, Hoglander J, et al. "Same same or different?" A review of reviews of person-centered and patientcentered care. Patient Educ Couns. 2019;102 (1):3-11.

14. Stannard C, Johnson M. Chronic pain management--can we do better? An interviewbased survey in primary care. Curr Med Res Opin. 2003;19(8):703-6.

15. Graneheim UH, Lundman B. Qualitative content analysis in nursing research: concepts, procedures and measures to achieve trustworthiness. Nurse Educ Today. 2004;24(2):10512.

16. Läkarförbund S. Vårdens styrning - En underlagsrapport [Health care Organisation report]. Stockholm; 2018.

17. Declaration of Helsinki: ethical principles for medical research involving human subjects.

18. O’brien CB, Harris BI, Beckman JT, Reed AD, Cook AD. Standards for Reporting Qualitative Research: A Synthesis of Recommendations. Acad Med. 2014;89(9):1245-51.

19. Skjutar Å, Müllersdorf M. Adapt, discover and engage: a qualitative interview study with patients living with chronic pain. J Nurs \& HC Chron Illn. 2010;2(4):254-61.

20. Hansson KS, Fridlund B, Brunt D, Hansson B, Rask M. The meaning of the experiences of persons with chronic pain in their encounters with the health service. Scand J Car Sci. 2011;25(3):444-50.

21. Werner A, Malterud K. It is hard work behaving as a credible patient: encounters between women with chronic pain and their doctors. Soc Sci \& Med. 2003;57(8):140919.

22. Thompson LE, Broadbent DJ, Bertino KM, Staiger KP. Do Pain-related Beliefs Influence Adherence to Multidisciplinary Rehabilitation?: A Systematic Review. The Clin J Pain. 2016;32(2):164-78. 
23. Karasawa Y, Yamada K, Iseki M, Yamaguchi M, Murakami Y, Tamagawa T, et al. Association between change in self-efficacy and reduction in disability among patients with chronic pain. PloS one. 2019;14(4):e0215404.

24. Tang KYN, Salkovskis MP, Hanna MM. Mental Defeat in Chronic Pain: Initial Exploration of the Concept. The Clin J Pain. 2007;23(3):222-32.

25. Alperstein D, Sharpe L. The Efficacy of Motivational Interviewing in Adults With Chronic Pain: A Meta-Analysis and Systematic Review. The J Pain. 2016;17(4):393-403.

26. Clarke KA, Iphofen R. Pain management. Believing the patient with chronic pain: a review of the literature. Brit Jour Nurs. 2005;14(9):490-3.

27. Howarth M, Warne T, Haigh C. Pain from the inside: understanding the theoretical underpinning of person-centered care delivered by pain teams. Pain Manag Nurs. 2014;15(1):340-8.

28. Becker KL. Tell me your dreams and goals: Structuring communication exchanges to improve patient-centered care with chronic pain patients. Appl Nurs Res. 2020;53. doi.org/10.1016/j.apnr.2020.151248.

29. Nøst TH, Steinsbekk A. 'A lifebuoy' and 'a waste of time': patients' varying experiences of multidisciplinary pain centre treatment- a qualitative study. BMC Heal Serv Res. 2019;19(1).

30. Koskinen C, Aho S, Nyholm L. Life with an unwelcome guest - caring in a context of protracted bodily pain. Scand J Car Sci. 2016;30(4):774-81.

31. Yorkston K, Johnson K, Boesflug E, Skala J, Amtmann D. Communicating about the experience of pain and fatigue in disability. Qual of Lif Res. 2010;19(2):243-51.

32. Matthias MS, Bair MJ, Nyland KA, Huffman MA, Stubbs DL, Damush TM, et al. Selfmanagement support and communication from nurse care managers compared with 
primary care physicians: a focus group study of patients with chronic musculoskeletal pain. Pain Manag Nurs. 2010;11(1):26-34.

33. Graneheim UH, Lindgren B-M, Lundman B. Methodological challenges in qualitative content analysis: A discussion paper. Nurs Edu Today. 2017;56:29-34. 